\title{
The Evaluation of Gender Effect in Treatment of Alveolar Cleft with Iliac Bone Graft By Means of Volumetric Analysis
}

\author{
Nesrin Saruhan ${ }^{1}$, Ümit Ertaş ${ }^{2}$ \\ ${ }^{1}$ Oral and Maxillofacial Surgery, Sakarya, Turkey. \\ ${ }^{2}$ Ataturk University Faculty of Dentistry, Department of Oral and Maxillofacial Surgery, Erzurum, Turkey.
}

Received: 21 April 2017 Accepted: 25 April 2017, Published online: 25 April 2017

(C) Ordu University Institute of Health Sciences, Turkey, 2017

\begin{abstract}
Objective: The purpose of this study was to evaluate of gender effect in treatment of alveolar cleft with iliac bone graft by means of volumetric analysis.

Methods: In this study; 22 patients with alveolar cleft including 13 unilateral, and 9 bilateral were treated with anterior iliac crest bone graft. Patients were divided into subgroups according to their gender. Cone Beam Computed Tomography scans were obtained preoperatively and postoperatively. 3D reconstruction of Cone Beam Computed Tomography images was made by using Mimics software. Preoperative alveolar cleft volume and postoperative newly formed bone volume was assessed volumetrically.

Results and Conclusion: The percentage of preoperative alveolar cleft volume in female ranged from 0.51 to $1.45 \mathrm{~cm} 3$ with a mean volume of $0.89 \pm 0.27 \mathrm{~cm} 3$, in male ranged from 0.72 to $2.04 \mathrm{~cm} 3$ with a mean volume of $1.11 \pm 0.36 \mathrm{~cm} 3$. The percentage of newly formed bone in female ranged from $47.02 \%$ to $80.09 \%$ with a mean percentage of $\% 68.23 \pm \% 9.43$, in male ranged from $50.70 \%$ to $77.49 \%$ with a mean percentage of $63.09 \% \pm 10.72 \%$. There is no statistically significant difference between the female and male for postoperative newly formed bone in treatment of alveolar cleft with iliac bone graft $(\mathrm{p}>0.05)$.

Key words: Congenital abnormalities, gender, three-dimensional imaging.
\end{abstract}

Address for correspondence/reprints:

Nesrin Saruhan

Telephone number: +902642781021

E-mail: dt_nesrin@yahoo.com

DOI: $10.19127 / \mathrm{mbsjohs.307346}$

\section{Introduction}

One of the most commonly encountered congenital anomalies of the head and neck region is the cleft lip and / or palate. It occur approximately 1 in 1000 births. Its prevalence varies depending on some factors such as race, geographical location, ethnic origin and gender. In our country, the rate of cleft lip and / or palate is 0.95 in 1000 and the rate of isolated cleft palate is 0.77 in 1000 . (Tunçbilek, Alikaşifoğlu, \& Akdallı, 1996) Alveolar clefts also accompany cleft lip and / or palate anomalies. (Ersoy, 2015)

There are many donor sites that are used as autogenous bone grafts in alveolar cleft treatment. However, among those, the most commonly used and the one that is accepted as gold standard is the iliac crest. Its advantages include low morbidity, creating an aesthetically acceptable scar, availability in sufficient amounts even in children, containing high amount of osteoblastic cells 
(cancellous bone) and enabling two teams to operate at the same time. (Brattstrom \& McWilliam, 1989)

For the assessment of the success of bone grafts in alveolar cleft treatment, clinical findings as well as radiological examinations are necessary. In order to assess the changes in bone volume, 3D imaging is definitely necessary.(Feichtinger, Mossbock, \& Karcher, 2007)

The aim of this study is to evaluate the effect of gender on the postoperatively obtained new bone volume via the method of $3 \mathrm{D}$ volumetric analysis in the treatment of alveolar cleft with platelet-rich fibrine (PRF) application and iliac bone graft.

\section{Methods}

Our study included 22 patients who were diagnosed radiologically and clinically with alveolar cleft were admitted to the Department of Oral and Maxillofacial Surgery, Faculty of Dentistry, Ataturk University between the years of 2013 and 2016. The scientific ethical conformity of this study was approved by the dated 27.09.2013 and numbered 21 decision of the Ethics Committee of the Faculty of Dentistry of Ataturk University.

Patients included in this study were free of systemic diseases, particularly platelet disorders (thrombocytopenia, thromboasthenia); had no other craniofacial anomaly except cleft lip and / or palate; had no any syndrome or congenital malformation that may influence the treatment or results of the study; had good oral hygiene; had no history of jaw irradiation; had no local pathology in maxilla that could interfere with surgery (Figure 1).

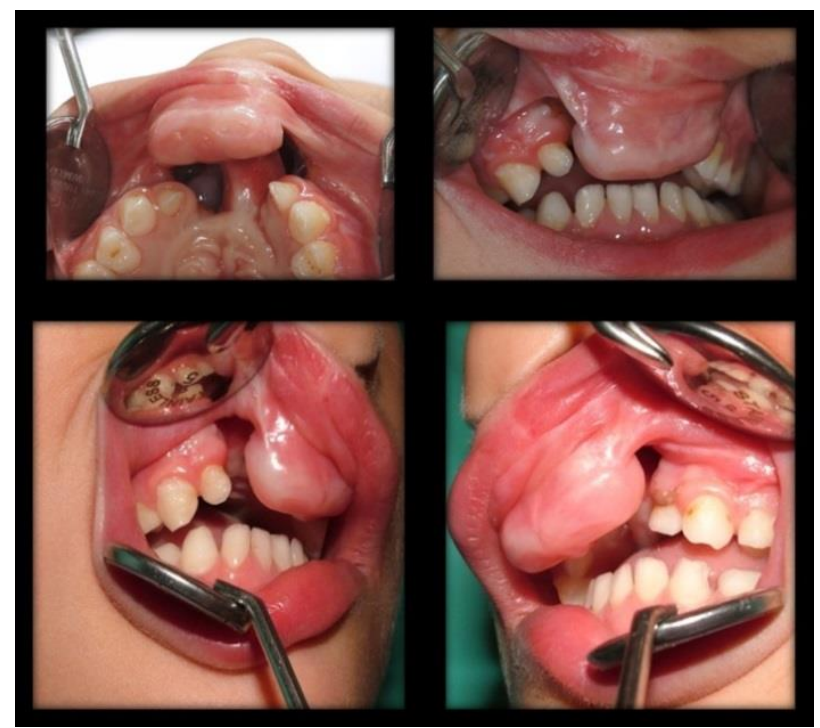

Figure 1: Oral image of the patient with bilateral alveolar cleft
The patients who underwent previous alveolar cleft repair but needed revision, who had any kind of medical or cooperation problem that may contradict the operation were excluded.

This study was conducted on a total of 31 alveolar cleft segments of 22 patients of whom 9 were male and 13 were female and 9 had bilateral and 13 had unilateral alveolar cleft. Their ages ranged between 6-28 years. The patients who were examined within the scope of this study were divided into groups according to their operation (group 1 and 2) and gender. They were grouped as following:

Group 1: A total of 17 segments which were used in 12 patients of whom 7 had unilateral, 5 had bilateral alveolar clefts and in whom only corticocancellous autogenous bone grafts harvested from the anterior iliac crest were used for alveolar cleft repair

Group 2: A total of 14 segments which were used in 10 patients of whom 6 had unilateral, 4 had bilateral alveolar cleft and in whom corticocancellous autogenous bone grafts harvested from the anterior iliac crest along with PRF were used for alveolar cleft repair.

The patients were taken into operation under general anesthesia with nasal endotracheal intubation. Oral and nasal mucosa was identified in the cleft region and the nasal mucosa was separated from the oral mucosa via dissection. Then the nasal mucosa was repaired using a 4.0 vicryl suture (Figure 2).

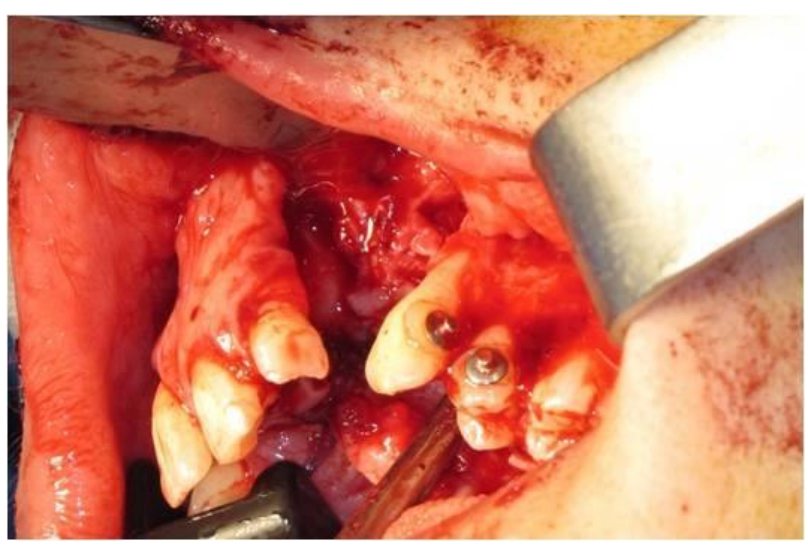

Figure 2: Preparation of the mucoperiostal flaps and repair of the nasal mucosa

In the anterior iliac crest, skin, subcutaneous, fascia and muscle layers were dissected with an incision of $4 \mathrm{~cm}$ which is distal and lateral to the superior spinal iliac so that the lateral femoral cutaneous nerve is 
protected. Corticocancellous block bone graft according to the amount of cleft was harvested from the medial surface of iliac crest by osteotom (Figure 3).

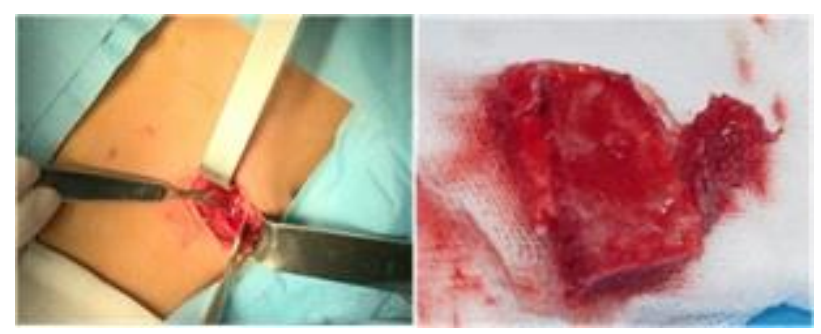

Figure 3: Corticocancellous bone graft harvesting from anterior iliac crest with osteotomy

Whereas cancellous bone graft was harvested from the medial part of the crest with the aid of curettes. Bone wax was placed in the medial region of anterior iliac crest where the bone graft was harvested. After hemostasis control, hemovac drain was placed and the wound area was closed primarily using 4.0 vicryl for subcutaneous tissues and 4.0 polypropylene sutures for skin in a manner that no dead space would be left.

After the corticocancellous bone grafts that were harvested from the anterior iliac crest were shaped according to the size of cleft line or lines, alveolar bone width was placed in a way that it would fill in the lower border of the anterior nasal aperture and lower border of the alveolar bone. In the patients of Group 2, PRF which was prepared at $3000 \mathrm{rpm}$ for 10 minutes was applied as a membrane on the bone graft. The lateral gingival mucoperiosteal flaps were slid in a manner that they would cover the graft and entire cleft.

The preoperative alveolar cleft volume and postoperative newly formed bone volume were calculated using Mimics Medical 17.0 software.

Statistical analysis was performed using the IBM SPSS Statistics 20 package program (Armonk, NY: IBM Corp.). The normal distribution of the data was assessed by the Kolmogorov-Smirnov test in the subgroups. The t-test was used for the independent samples to compare the binary subgroups. Two-way analysis of variance was used to compare the interactions between subgroups.

\section{Results}

Our study was carried out on 22 patients whose ages ranged between 6 and 28 years (mean age: $17.71 \pm 5.4$ years $)$. Of them, nine $(40.9 \%)$ were male and $13(59.1 \%)$ were female. Nine patients (40.9\%; six were female, three were male) had bilateral and 13 patients (59.1\%; seven were female, six were male) had unilateral alveolar cleft. Of 12 patients in group 1, $7(58.3 \%)$ had unilateral and $5(41.7 \%)$ had bilateral alveolar cleft which was 17 in total. Of 10 patients in group 2, $6(60 \%)$ had unilateral and $4(40 \%)$ had bilateral alveolar cleft which was 14 in total. Each cleft was considered as a segment and the preoperative cleft volumes and the postoperative newly formed bone volumes of 31 alveolar cleft segments from a total of 22 patients were measured in terms of $\mathrm{cm} 3$.

Age, preoperative alveolar cleft volume, postoperative newly formed bone volume and percentage values were calculated. These data were evaluated by taking the groups and gender into account.

In this study, preoperative cleft volume, postoperative newly formed bone volume and the distribution of percentage variables were analyzed by Kolmogorov-Simirnov test and the distribution in each of three variables was found to show normal distribution ( $p>0.05$ ). Also, no difference was detected between the groups in terms of the variable of preoperative alveolar cleft volume. Therefore, the groups were considered equal in terms of preoperative cleft volume preoperatively. Since there was normal distribution, parametric tests were performed and t-test was performed in independent groups.

The percentage of newly formed bone in group 2 ranged from $50.70 \%$ to $80.09 \%$, with a mean percentage of $68.21 \% \pm 10.80$ percent. In group 1 , the percentage of bone formation ranged from $47.02 \%$ to $79.23 \%$, with a mean percentage of $64.62 \% \pm 9.49$ percent.

Descriptive statistics were performed for gender data (Table 1). In the binary comparison of the data, no statistically significant difference was found between the genders in terms of age, preoperative alveolar cleft volume, postoperative newly formed bone volume and percentage values ( $p>0.05$ ) (Table 2).

There was no statistically significant difference between the groups and gender in terms of percentage value ( $>0.05)$ (Table 3$)$. Also, in the two-way analysis of variance, group gender interaction was not found to be statistically significant but marginally $(\mathrm{p}<0.10)$ (Table 4). 
Tablo 1: Descriptive values of gender data

\begin{tabular}{ccccccc}
\hline \multirow{2}{*}{ Gender } & $\mathbf{n}$ & Average & $\begin{array}{c}\text { Standard } \\
\text { deviation }\end{array}$ & Minimum & Maximum \\
\hline \multirow{4}{*}{ Male } & Age & 12 & 19.17 & 4.85 & 13 & 28 \\
& Preoperative & 12 & 1.11 & 0.36 & 0.72 & 2.04 \\
& Postoperative & 12 & 0.68 & 0.16 & 0.52 & 1.08 \\
& Percent & 12 & 63.09 & 10.72 & 50.70 & 77.49 \\
\hline \multirow{4}{*}{ Female } & Age & 19 & 16.69 & 5.60 & 6 & 23 \\
& Preoperative & 19 & 0.89 & 0.27 & 0.51 & 1.45 \\
& Postoperative & 19 & 0.61 & 0.22 & 0.32 & 1.01 \\
& Percent & 19 & 68.23 & 9.43 & 47.02 & 80.09 \\
\hline
\end{tabular}

Tablo 2: Binary comparison of gender data

\begin{tabular}{cccccc} 
& \multicolumn{2}{c}{ Average test of equality } & \multicolumn{3}{c}{ Equality test of the averages ( $\mathrm{t}$ test) } \\
& $\mathbf{F}$ & $\mathbf{p}$ & $\mathbf{t}$ & $\mathbf{p}$ & Average Difference \\
\hline Age & 1.692 & 0.204 & 1.210 & 0.236 & 2.377 \\
\hline Preoperative & .041 & 0.842 & 1.927 & 0.064 & 0.22142 \\
\hline Postoperative & 4.740 & 0.038 & 0.861 & 0.396 & 0.06396 \\
\hline Percent & 0.699 & 0.410 & 1.402 & 0.172 & -5.13531 \\
\hline \multicolumn{7}{c}{} & * Statistically significant difference. $(\mathrm{p}<0.05)$. &
\end{tabular}

Tablo 3: Percentage values by groups and gender

\begin{tabular}{ccccc}
\hline Group & Gender & Average & $\begin{array}{c}\text { Standart } \\
\text { deviation }\end{array}$ & $\mathbf{n}$ \\
\hline \multirow{3}{*}{ Group 1 } & Male & 61.08 & 6.77 & 4 \\
& Female & 65.70 & 10.16 & 13 \\
& Total & 64.62 & 9.49 & 17 \\
\hline \multirow{3}{*}{ Group 2 } & Male & 64.10 & 12.54 & 8 \\
& Female & 73.69 & 4.49 & 6 \\
& Total & 68.21 & 10.80 & 14 \\
\hline \multirow{2}{*}{ Total } & Male & 63.09 & 10.71 & 12 \\
& Female & 68.23 & 9.43 & 31 \\
\hline
\end{tabular}

Tablo 4: Variance analysis of the percentage values for group and gender factors

\begin{tabular}{ccccc}
\hline Variation Source & df & Squares average & F & p \\
\hline Group & 1 & 196.118 & 2.055 & 0.163 \\
Gender & 1 & 326.991 & 3.426 & $\mathbf{0 . 0 7 5}^{+}$ \\
Gruop * Gender interaction & 1 & 39.721 & 0.416 & 0.524 \\
Error & 27 & 95.456 & & \\
Total & 31 & & & \\
\hline
\end{tabular}

${ }^{+}$Marginally significant difference $(\mathrm{p}<0.10)$ 


\section{Discussion}

Cleft lip and / or palate are the most common congenital malformations of the head and neck region. (Bahr \& Coulon, 1996) As it can be formed separately in the lip and palate, it may involve both of them. (HALICIOĞLU \& KOÇAL, 2016) Alveolar clefts accompany these malformations. (Ersoy, 2015) There are many treatment protocols for alveolar cleft, and alveolar bone grafting constitutes the basis of these treatment protocols. (Baqain, Anabtawi, Karaky, \& Malkawi, 2009)

In addition to clinical evaluations, especially radiological assessments are needed in order to objectively evaluate the postoperative newly formed bone after alveolar bone grafting. Conventional or $3 \mathrm{D}$ radiological methods can be used for this purpose. (Amanat \& Langdon, 1991) Recently, the use of computerized tomography (CT) for the assessment of bone grafts that is used in the treatment of alveolar clefts has become increasingly popular. (Tai, Sutherland, \& McFadden, 2000) Since CT does not have anatomic superimpositions compared to conventional radiographs, it yields more accurate results and has better image quality. However, considering the relation of traditional conventional CT procedures with high levels of radiation dose, alternative CT procedures were investigated in an attempt to perform bone imaging and modeling so as to decrease the effective radiation dose for patients without causing a significant loss in image quality. From this point of view, cone-beam computerized tomography (CBCT) constituted a promising potential for oral and craniofacial imaging. (Sukovic, 2003) In our study, CBCT was preferred to CT because of its abilities of reconstructing three-dimensional images with a single low radiation dose and its easy application.

Numerous 3D software programs are used for volumetric calculations of alveolar clefts. Among these, SimPlant, Mimics, Radipia, Amira, Maxilim, Vitrea, Ondemand, Allura, V-Works, Romexis are the most frequently used ones. (Choi et al., 2012) In our study, Mimics software was preferred because it gives very precise results especially in $3 \mathrm{D}$ volume calculations.

There are many donor sites that are used as autogenous bone grafts in alveolar cleft treatment. However, among those, the most commonly used and the one that is accepted as gold standard is the iliac crest. Bone grafts can be harvested from both the anterior and posterior part of iliac crest. Posterior iliac crest is usually preferred in the cases with large clefts and in the situations which require a greater amount of bone graft.(Brattstrom \& McWilliam, 1989) In our study, alveolar cleft volume was measured preoperatively and there was no need for bone graft to be harvested from the posterior iliac, thus corticocancellous bone graft was harvested from the anterior iliac crest in all cases.

Another autogenous bone donor site that is used for alveolar cleft repair is the mandibular symphysis region. In the studies of Kilinc et al.(Kilinc, Saruhan, Ertas, Korkmaz, \& Kaymaz, 2017) on the children and adults with unilateral or bilateral alveolar clefts, they reported that the mandibular symphysis zone had adequate bone volume in adult patients with unilateral alveolar cleft.

The most important point of alveolar cleft treatment is the postoperative success of bone grafts. Tai et al. (Tai, et al., 2000) carried out the follow-up of a total of 14 patients with unilateral or bilateral cleft lip and palate (a total of 17 alveolar clefts) who were operated with iliac bone grafting, in the preoperative, early postoperative period and at one year with CT. When the volumetric analysis of bone resorption was performed on coronal and axial sections, the bone loss ranged between $42.5 \%$ and $43.7 \%$ with a mean of $43.1 \%$. In other studies, it was reported that high-rate resorption was observed especially within the first year after grafting.(Shawky \& Seifeldin, 2015)

There are many factors which affect postoperative bone volume in alveolar cleft treatment. Considering that gender may be one of affecting factors, the effect of gender on alveolar cleft repair that was performed with the corticocancellous bone grafting which was harvested from the iliac crest was investigated. Twelve segment alveolar clefts in males and 19 segment alveolar clefts in females were evaluated. In the gender subgroups, the parameters of age, preoperative alveolar cleft volume, the postoperative newly formed bone and percentage values were evaluated and no statistically significant difference was found in any of these data. However, the postoperative newly formed bone volume was found to be $68.25 \%$ in the females and $63.09 \%$ in the males. Therefore, although percentage values were not statistically significant but they were higher in the females than the males. The reason of this was considered to be due to the fact that the mean age of the females $(16.69 \pm 5.6$ years) was lower than that of the males 
$(19.17 \pm 4.85$ years $)$ or the preoperative cleft volume in females (mean $0.89 \mathrm{~cm} 3$ ) was lower than that of the males (mean $1.11 \mathrm{~cm} 3$ ). Also, no statistically significant difference was found between the groups and genders, but in group 1, in group 2 and in total, the success in the females was found to be higher than that of the males in terms of postoperative newly formed bone volume. Therefore, whether there was an interaction between the groups and gender or not was evaluated and no statistically but a marginally significant difference was detected. Thus, it was considered that in case of conducting studies which include higher number of cases, a statistical significance could be obtained between the genders and groups.

\section{Conclusion}

When the effect of gender on the postoperative newly formed bone volume in alveolar cleft treatment with iliac bone grafting and PRF was examined with volumetric analysis in the patients of group 1 and 2, no statistically significant difference was found between the females and males in terms of the postoperative newly formed bone volume.

Ethics Committee Approval: Ethics committee approval was received for this study from Faculty of Dentistry Clinical Research Ethics Committee of Ataturk University.

Peer-review: Externally peer-reviewed.

Author Contributions: Concept - U.E. Design UE; Supervision U.E.; Materials - UE; Data Collection and/or Processing - N.S.; Analysis and/or Interpretation - N.S.; Literature Review N.S.; Writing -N.S.; Critical Review - U.E.

Conflict of Interest: No conflict of interest was declared by the authors.

Financial Disclosure: The authors declared that this study hasn't received no financial support.

\section{References}

Amanat, N., \& Langdon, J. D. (1991). Secondary alveolar bone grafting in clefts of the lip and palate. Journal of cranio-maxillo-facial surgery : official publication of the European Association for Cranio-Maxillo-Facial Surgery, 19(1), 7-14.
Bahr, W., \& Coulon, J. P. (1996). Limits of the mandibular symphysis as a donor site for bone grafts in early secondary cleft palate osteoplasty. International journal of oral and maxillofacial surgery, 25(5), 389-393.

Baqain, Z. H., Anabtawi, M., Karaky, A. A., \& Malkawi, Z. (2009). Morbidity from anterior iliac crest bone harvesting for secondary alveolar bone grafting: an outcome assessment study. Journal of oral and maxillofacial surgery : official journal of the American Association of Oral and Maxillofacial Surgeons, 67(3), 570575. doi: 10.1016/j.joms.2008.09.023

Brattstrom, V., \& McWilliam, J. (1989). The influence of bone grafting age on dental abnormalities and alveolar bone height in patients with unilateral cleft lip and palate. [Review]. European journal of orthodontics, 11(4), 351-358.

Choi, H. S., Choi, H. G., Kim, S. H., Park, H. J., Shin, D. H., Jo, D. I., . . . Uhm, K. I. (2012). Influence of the alveolar cleft type on preoperative estimation using 3D CT assessment for alveolar cleft. Archives of plastic surgery, 39(5), 477-482.

Ersoy, U. (2015). Kemik Grefti ile Rekonstrüksiyon In F. Özgur (Ed.), Dudak-Damak Yarıkları (pp. 199-210). Ankara: Atlas Kitapçılık.

Feichtinger, M., Mossbock, R., \& Karcher, H. (2007). Assessment of bone resorption after secondary alveolar bone grafting using threedimensional computed tomography: a three-year study. The Cleft palate-craniofacial journal : official publication of the American Cleft Palate-Craniofacial Association, 44(2), 142-148. doi: $10.1597 / 06-047.1$

Halicioğlu, k., \& Koçal, g. k. (2016). Damak yarikli hastalarda alveoler kemik greftlemesi. Atatürk Üniversitesi Diş Hekimliği Fakültesi Dergisi, 26(1).

Kilinc, A., Saruhan, N., Ertas, U., Korkmaz, I. H., \& Kaymaz, I. (2017). An Analysis of Mandibular Symphyseal Graft Sufficiency for Alveolar Cleft Bone Grafting. Journal of Craniofacial Surgery, 28(1), 147-150.

Shawky, H., \& Seifeldin, S. A. (2015). Does Platelet-Rich Fibrin Enhance Bone Quality and Quantity of Alveolar Cleft Reconstruction? The Cleft palate-craniofacial journal. 
Sukovic, P. (2003). Cone beam computed tomography in craniofacial imaging. [Comparative Study Research Support, U.S. Gov't, P.H.S.]. Orthodontics \& craniofacial research, 6 Suppl 1, 31-36; discussion 179-182.

Tai, C. C., Sutherland, I. S., \& McFadden, L. (2000). Prospective analysis of secondary alveolar bone grafting using computed tomography. [Evaluation Studies Research Support, Non-U.S. Gov't]. Journal of oral and maxillofacial surgery : official journal of the American Association of Oral and Maxillofacial Surgeons, 58(11), 1241-1249; discussion 1250. doi: 10.1053/joms.2000.16623

Tunçbilek, E., Alikaşifoğlu, M., \& Akdallı, B. (1996). Türkiye'de konjenital malformasyon sıklığı, dağılımı, risk faktörleri ve yenidoğanların antropometrik değerlendirilmesi. Ankara TÜBİTAK Matbaası, 94. 